\title{
Fluid Intake and Colorectal Cancer Risk in the Netherlands Cohort Study
}

Citation for published version (APA):

Simons, C. C. J. M., Leurs, L. J., Weijenberg, M. P., Schouten, L. J., Goldbohm, R. A., \& van den Brandt, P. A. (2010). Fluid Intake and Colorectal Cancer Risk in the Netherlands Cohort Study. Nutrition and Cancer-An International Journal, 62(3), 307-321. https://doi.org/10.1080/01635580903407098

Document status and date:

Published: 01/01/2010

DOI:

10.1080/01635580903407098

Document Version:

Publisher's PDF, also known as Version of record

Document license:

Taverne

Please check the document version of this publication:

- A submitted manuscript is the version of the article upon submission and before peer-review. There can be important differences between the submitted version and the official published version of record.

People interested in the research are advised to contact the author for the final version of the publication, or visit the DOI to the publisher's website.

- The final author version and the galley proof are versions of the publication after peer review.

- The final published version features the final layout of the paper including the volume, issue and page numbers.

Link to publication

\footnotetext{
General rights rights.

- You may freely distribute the URL identifying the publication in the public portal. please follow below link for the End User Agreement:

www.umlib.nl/taverne-license

Take down policy

If you believe that this document breaches copyright please contact us at:

repository@maastrichtuniversity.nl

providing details and we will investigate your claim.
}

Copyright and moral rights for the publications made accessible in the public portal are retained by the authors and/or other copyright owners and it is a condition of accessing publications that users recognise and abide by the legal requirements associated with these

- Users may download and print one copy of any publication from the public portal for the purpose of private study or research.

- You may not further distribute the material or use it for any profit-making activity or commercial gain

If the publication is distributed under the terms of Article $25 \mathrm{fa}$ of the Dutch Copyright Act, indicated by the "Taverne" license above, 


\section{Fluid Intake and Colorectal Cancer Risk in the Netherlands Cohort Study}

Colinda C. J. M. Simons, Lina J. Leurs, Matty P. Weijenberg, Leo J. Schouten, R. Alexandra Goldbohm \& Piet A. van den Brandt

To cite this article: Colinda C. J. M. Simons, Lina J. Leurs, Matty P. Weijenberg, Leo J. Schouten , R. Alexandra Goldbohm \& Piet A. van den Brandt (2010) Fluid Intake and Colorectal Cancer Risk in the Netherlands Cohort Study, Nutrition and Cancer, 62:3, 307-321, DOI: 10.1080/01635580903407098

To link to this article: https://doi.org/10.1080/01635580903407098

央 Published online: 31 Mar 2010.

Submit your article to this journal

Џ Article views: 199

Q View related articles ¿

Citing articles: 4 View citing articles 


\title{
Fluid Intake and Colorectal Cancer Risk in the Netherlands Cohort Study
}

\author{
Colinda C. J. M. Simons, Lina J. Leurs, Matty P. Weijenberg, and Leo J. Schouten \\ Maastricht University, GROW—School for Oncology and Developmental Biology, Maastricht, \\ the Netherlands
}

\author{
R. Alexandra Goldbohm \\ TNO Quality of Life, Leiden, the Netherlands
}

\section{Piet A. van den Brandt}

Maastricht University, GROW—School for Oncology and Developmental Biology, Maastricht, the Netherlands

Total fluid intake, specifically water intake, has been suggested to protect against colorectal cancer. We examined the association of total fluid intake with colorectal cancer endpoints and possible effect modification by fiber intake within the Netherlands Cohort Study $(N=120,852)$. We also investigated intake of specific beverages. After $13.3 \mathrm{yr}, 1,443$ male and 1,040 female colorectal cancer cases with complete baseline questionnaires were available for case-cohort analyses. Multivariate analyses showed no doseresponse relationship of total fluid intake and intake of specific beverages with the risk of overall colorectal, proximal, and distal colon cancer. For rectal cancer risk in men, there was a nonsignificant positive trend for total fluid intake $[>1,500 \mathrm{vs} . \leq 1,000 \mathrm{ml} / \mathrm{day}$ : $\mathrm{HR}=1.50,95 \% \mathrm{CI}=0.95-2.37, P$ trend $=0.08)$ and a significant positive trend for coffee intake ( $>6$ vs. $\leq 2$ cups/day: $H R=1.60$, 95\% $\mathrm{CI}=0.96-2.66, P$ trend $=0.05)$. However, a nonsignificant positive trend for total fluid intake was no longer observed when additionally adjusting for coffee intake. Tests for interaction were not significant. In conclusion, total fluid intake was not associated with colorectal cancer risk in either men or women. There was no evidence that fiber intake modified associations. Of the specific beverages, coffee intake was positively associated with rectal cancer risk in men.

\section{INTRODUCTION}

Total fluid intake, specifically water intake, has been suggested to protect against colorectal cancer by reducing the bowel transit time and therefore the time that carcinogens are in contact

Submitted 30 January 2009; accepted in final form 7 June 2009.

Address correspondence to Piet van den Brandt, Maastricht University, Faculty of Health, Medicine and Life Sciences, Department of Epidemiology, P.O. Box 616, 6200 MD Maastricht, the Netherlands, Phone: +31 43-3882361. Fax: +31 43-3884128. E-mail: pa.vandenbrandt@epid.unimaas.nl with the colonic mucosa $(1,2)$. Nonnutritive dietary components such as water, however, have rarely been studied, and as a result, the epidemiologic evidence for a protective effect of total fluid intake and/or water intake on colorectal cancer risk is scarce.

Three previous case-control studies but no cohort studies have supported an inverse association of water intake with colorectal cancer endpoints in either men or women $(1,3,4)$. Of these, one also reported an inverse association with total fluid intake (3). A fourth case-control study that investigated the association of water intake with rectal cancer risk found no association yet observed an increased risk in men with both a low water intake and a low fiber intake (5). A combined effect of total fluid intake and fiber intake may be plausible, seeing that fiber intake may reduce the bowel transit time by bulking feces provided fluid intake is sufficient (6).

In contrast with the aforementioned, numerous studies have investigated the association of intake of specific beverages with colorectal cancer risk. Consumption of alcoholic beverages, for example, has been associated with an increased risk, whereas milk intake has been associated with a decreased risk (7). A possible explanation for these associations may be the carcinogenic effects of ethanol in alcoholic beverages and the anticarcinogenic effects of calcium in milk (7). For coffee and tea, which are major contributors to total fluid intake, findings of an association with colorectal cancer endpoints have been inconsistent (8-11). Tea, nevertheless, is hypothesized to be protective because of the anticarcinogenic activities of catechins present in tea (12).

In this study, we prospectively investigated the association of total fluid intake with colorectal cancer endpoints and possible effect modification by fiber intake within the Netherlands Cohort Study (NLCS) on diet and cancer. In addition, we investigated whether associations differ with intake of specific beverages, that is, water, coffee, tea, milk, and alcoholic beverages. 


\section{METHODS}

\section{Study Population}

The NLCS comprises 58,279 men and 62,573 women who were 55 to $69 \mathrm{yr}$ and completed a mailed self-administered questionnaire at baseline in September 1986. A case-cohort approach was used for data processing and analysis, enumerating incident cancer cases from the entire cohort and calculating the accumulated person time at risk from a random subcohort of 5,000 members who were taken from the cohort at baseline and followed up for vital status. All subcohort members contributed to the person time at risk until they became colorectal cancer cases or otherwise censored. A detailed description of the study design can be found elsewhere (13). The NLCS has been approved by the institutional review boards of the TNO Nutrition and Food Research Institute (Zeist, the Netherlands) and Maastricht University (Maastricht, the Netherlands).

\section{Data Collection}

Habitual consumption of foods and beverages during the preceding year and other risk factors were measured at baseline using a mailed self-administered questionnaire. For the dietary part, the questionnaire included a 150-item, semiquantitative, food frequency questionnaire (FFQ). Questionnaire data were key-entered and processed in a manner blinded to subcohort or case status. Nutrient intakes were calculated using the Dutch food composition table 1986-1987 (14). The FFQ was shown to be a valid instrument when tested against a 9-day diet record (15) and a good indicator of nutrient intake over a period of at least $5 \mathrm{yr}$ when tested for reproducibility (16).

\section{Assessment of Fluid Intake}

Total fluid intake in this study refers to intake of all fluids through beverages, not food. To assess beverage consumption, the FFQ contained questions on the consumption of (mineral) water, coffee, tea, milk (i.e., milk, buttermilk, cocoa), soft drinks, juices, soup, and alcoholic beverages. The FFQ also contained an open-ended question to account for any foods or beverages used at least once per week but not included in the questionnaire. For coffee and tea, subjects were asked to indicate whether they drank coffee or tea and if so, how many cups per day were taken. For all other beverages, subjects were asked to indicate how often on a scale of 7 frequency categories a certain quantity (i.e., number of glasses or cups) was consumed. The average content of household units was established during the validation study and measured $125 \mathrm{ml}$ for a coffee/tea cup, $175 \mathrm{ml}$ for a glass, $250 \mathrm{ml}$ for a soup bowl, $200 \mathrm{ml}$ for a beer glass, 105 $\mathrm{ml}$ for a wine glass, $80 \mathrm{ml}$ for a sherry glass, and $45 \mathrm{ml}$ for a liqueur/liquor glass (15). Consumption in $\mathrm{ml}$ per day could thus be calculated by multiplying the frequency of intake with the average content of a cup, particular glass, or bowl. The Pearson correlation coefficient between total dietary water intake (i.e., from beverages and foods) as assessed by the questionnaire and as estimated from the 9-day diet record was .73. Furthermore, the Spearman correlation coefficient was .63 for mean daily intake of nonalcoholic beverages and .89 for mean daily intake of alcoholic beverages (15). No specific reliability estimates for intake of beverages were available.

\section{Ascertainment of Cases}

Incident colorectal cancer cases were ascertained through annual record linkage with PALGA ((17); the Netherlands nationwide pathology registry) and the Netherlands population-based cancer registry (18) and had to be histologically confirmed. Excluded were subjects who reported a history of cancer other than nonmelanoma skin cancer at baseline and subjects for whom the dietary baseline questionnaire was inconsistent or incomplete; 1 incident colorectal cancer case was excluded because it was diagnosed with malignant melanoma located in the rectum. After $13.3 \mathrm{yr}$ of follow-up (i.e., from September 1986 to December 1999), 2,191 male and 2,247 female subcohort members and 1,443 male and 1,040 female colorectal cancer cases were available for analysis. Male colorectal cancer cases could be subdivided into 402 proximal colon cancer cases (International Classification of Diseases for Oncology, first edition, Codes 153.0, 153.1, 153.4, 153.5 and 153.6), 479 distal colon cancer cases (Codes 153.2, 153.3 and 153.7) and 375 rectal cancer cases (Code 154.1). For female colorectal cancer cases, the numbers were 414, 317, and 196, respectively. The remaining cases were rectosigmoid cancer cases (Code 154.0) or colon cancer cases that could not be classified as either proximal or distal colon cancer cases. These were only included when analyzing risk of overall colorectal cancer because risk of rectosigmoid cancer and risk of colon cancer were not analyzed separately.

\section{Statistical Analysis}

Hazard ratios (HR) and corresponding 95\% confidence intervals (CI) for colorectal cancer overall and at subsites were estimated across natural categories of intake using Cox proportional hazards model using Stata software (Stata Corp., College Station, TX). Besides total fluid intake, intake of coffee, tea, milk, and alcoholic beverages (in terms of volume) were investigated in relation to colorectal cancer endpoints separately because according to the literature, these specific beverages may be associated with colorectal cancer risk and because these specific beverages are highly consumed in the Dutch population and most likely explain the variation in total fluid intake. In addition, although specific beverages mainly consist of water, water intake was investigated separately because water is free of the specific components present in coffee, tea, milk, and alcoholic beverages that may explain potential effects of these beverages on colorectal cancer risk. For total fluid intake, coffee intake, and tea intake, the lowest category of intake was taken as the reference category. For intake of water, milk, and alcoholic beverages, the nonconsumer group was taken as the reference category. Analyses were also done on a continuous 
scale with an increment of $100 \mathrm{ml} /$ day. To account for the additional variance introduced by sampling the subcohort from the entire cohort, standard errors were estimated using the robust Huber-White sandwich estimator (19). Because in the literature, sex-specific results have been heterogeneous $(1,3-5)$, HRs and 95\% CIs were estimated for men and women separately. The proportional hazards assumption was tested using the scaled Schoenfeld residuals (20). When according to this test, the proportional hazards assumption appeared to be violated, the hazard curves were inspected visually. To test for dose-response relationships across categories of intake, ordinal exposure variables were fitted as continuous terms.

HRs and 95\% CIs were estimated with an age-adjusted model and a multivariate model adjusted for potential confounders. On the basis of previous literature, the following variables besides age were selected a priori for inclusion in the multivariate model: family history of colorectal cancer (yes-no), physical activity at the longest held job $(<8 \mathrm{~kJ} / \mathrm{min}, 8-12 \mathrm{~kJ} / \mathrm{min}$, $>12 \mathrm{~kJ} / \mathrm{min}$; only for men), nonoccupational physical activity (<30 min/day, 30-60 min/day, 60-90 min/day, >90 min/day), smoking status (never, ex, currently), body mass index (BMI; $\left.\mathrm{kg} / \mathrm{m}^{2}\right)$, ethanol intake $(\mathrm{g} /$ day), meat intake $(\mathrm{g} / \mathrm{day})$, processed meat intake (g/day), and fiber intake (g/day). Other potential confounders were included if these introduced a more than $10 \%$ change in estimates or significantly contributed to the model. Considered were diabetes, supplement use, use of hormonal replacement therapy after menopause, educational level, total energy intake, folate intake, $\beta$-carotene intake, vitamin B6 intake, vitamin $C$ intake, vitamin $\mathrm{E}$ intake, fruit intake, vegetable intake, calcium intake, energy-adjusted total fat intake, magnesium intake, and iron intake. Of these, educational level (primary school, lower vocational, junior high school, higher vocational/university), folate intake (g/day), and vitamin B6 intake (g/day) contributed significantly to the model and were thus included. In analyzing the association of intake of specific beverages with colorectal cancer endpoints, we mutually adjusted for fluid intake from other fluids because we were interested in specific beverages as contributors to total fluid intake.

Interaction of total fluid intake with fiber intake was tested using cross-product terms between categories of total fluid intake and sex-specific tertiles of fiber intake. To evaluate a possible combined effect of total fluid intake and fiber intake, HRs for colorectal cancer endpoints were estimated by including indicator variables in the regression model, representing categories of total fluid intake by sex-specific tertiles of fiber intake. The combination of the lowest category of total fluid intake and the lowest tertile of fiber intake was used as the reference category.

In the case that an association of total fluid intake with colorectal cancer endpoints was found, we checked whether frequency of constipation (never, seldom, sometimes/often/very often) may be an intermediate factor in this association by adjusting for it in the multivariate model. Information on frequency of constipation was only available for men. We also performed a sensitivity analysis calculating HRs and 95\% CIs for the associ- ation of total dietary water intake (g/day) as calculated using the Dutch food composition table (14) with colorectal cancer endpoints to check whether estimates differed as compared to those for the association of total fluid intake with colorectal cancer endpoints. Underlying this sensitivity analysis is that although an individual's total water intake may be most easily altered through intake of fluids, a considerable part of one's total water intake is ingested through foods, with estimates ranging from $20-28 \%$ in the literature (21). All analyses were repeated excluding the first $2 \mathrm{yr}$ of follow-up to check for the influence of preclinical disease. In all analyses, statistical significance was indicated by a $P$ value smaller than 0.05 for 2 -sided testing.

\section{RESULTS}

Baseline characteristics are described in Table 1 for 1,832 male and 2,045 female subcohort members and 1,260 male and 939 female colorectal cancer cases that were available for analysis after excluding those with missings on potential confounders. The mean (SD) total fluid intake among male and female subcohort members was 1,457 (441) $\mathrm{ml} /$ day and 1,347 (404) $\mathrm{ml} / \mathrm{day}$, respectively. The median follow-up time was $7.8 \mathrm{yr}$ for male colorectal cancer cases and $7.5 \mathrm{yr}$ for female colorectal cancer cases. The accumulated person time at risk among male and female subcohort members was 21,394 and $25,381 \mathrm{yr}$, respectively.

Table 2 shows the age-adjusted and multivariate HRs (95\% CIs) for the association of total fluid intake with the risk of colorectal cancer overall and at subsites. After adjustment for potential confounders, no association of total fluid intake with overall colorectal cancer risk was observed in either men or women. Analyses for colorectal cancer subsites showed no association with proximal or distal colon cancer risk, yet a nonsignificant positive trend in the association of total fluid intake with rectal cancer risk was present in men $(P$ trend $=0.08)$. HRs for rectal cancer in men who consumed $\leq 1,000,>1,000$ $1,250,>1,250-1,500$, and $>1,500 \mathrm{ml}$ of fluids per day were 1.00 (reference), 1.26 (95\% CI = 0.78-2.05), 1.15 (95\% CI = $0.71-1.86)$, and $1.50(95 \% \mathrm{CI}=0.95-2.37)$.

Tests for interaction between categories of total fluid intake and tertiles of fiber intake were not significant in either men or women (Table 3). The results for a possible combined effect of total fluid intake and fiber intake on overall colorectal cancer risk are shown in Table 3. A significantly lower risk of overall colorectal cancer was observed in men consuming $>1,250$ $1,500 \mathrm{ml}$ of fluids per day in the second tertile of fiber intake as compared with those consuming $\leq 1,000 \mathrm{ml}$ of fluids per day in the first tertile of fiber intake (HR $=0.66,95 \% \mathrm{CI}=0.43-1.00)$. However, no trend in the association of total fluid intake with overall colorectal cancer risk was evident, and the possibility that a significant finding may have occurred by chance has to be acknowledged. When analyses were done for colorectal cancer subsites, there were no significant associations for combinations of total fluid intake and fiber intake. However, when total fluid 


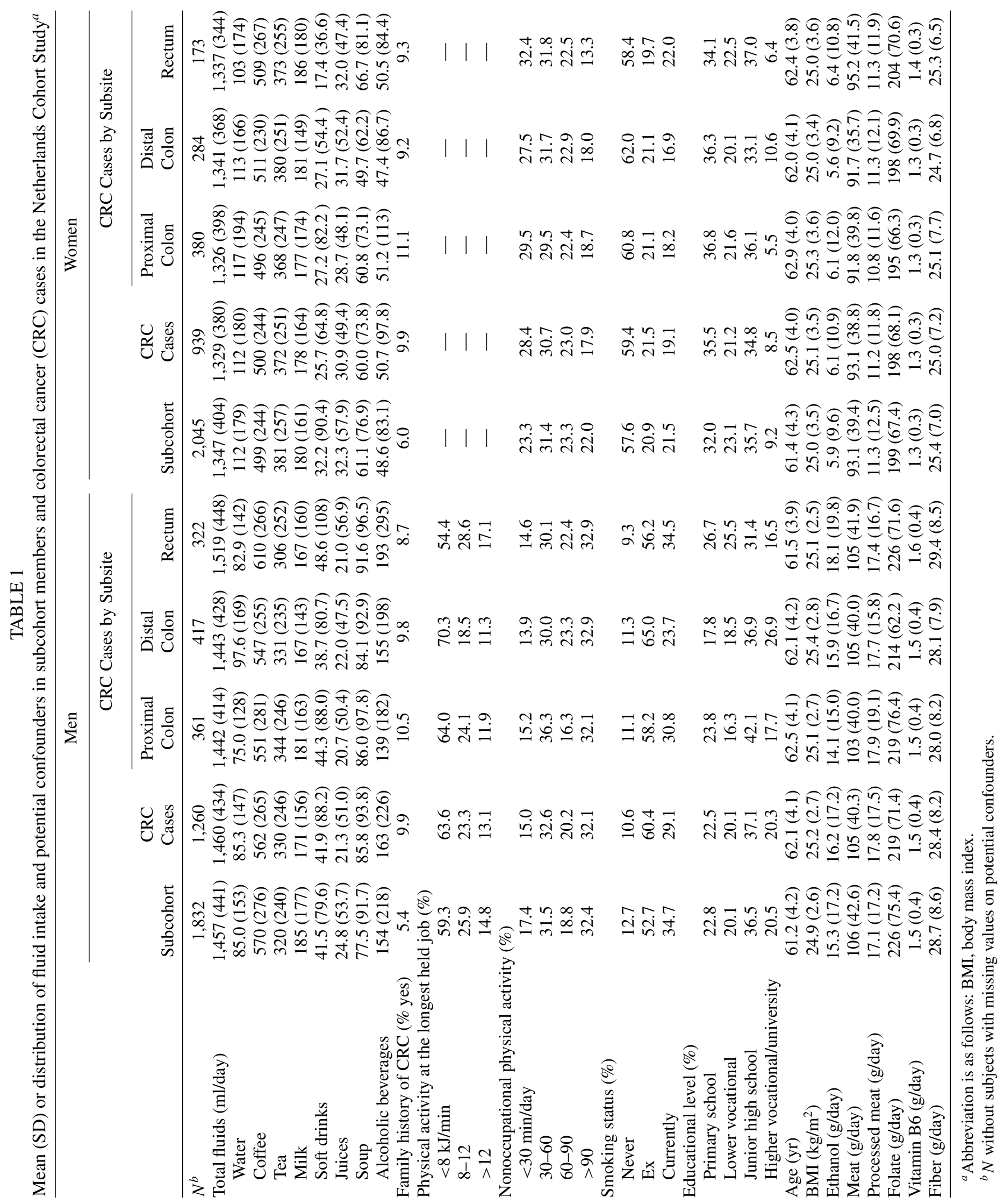




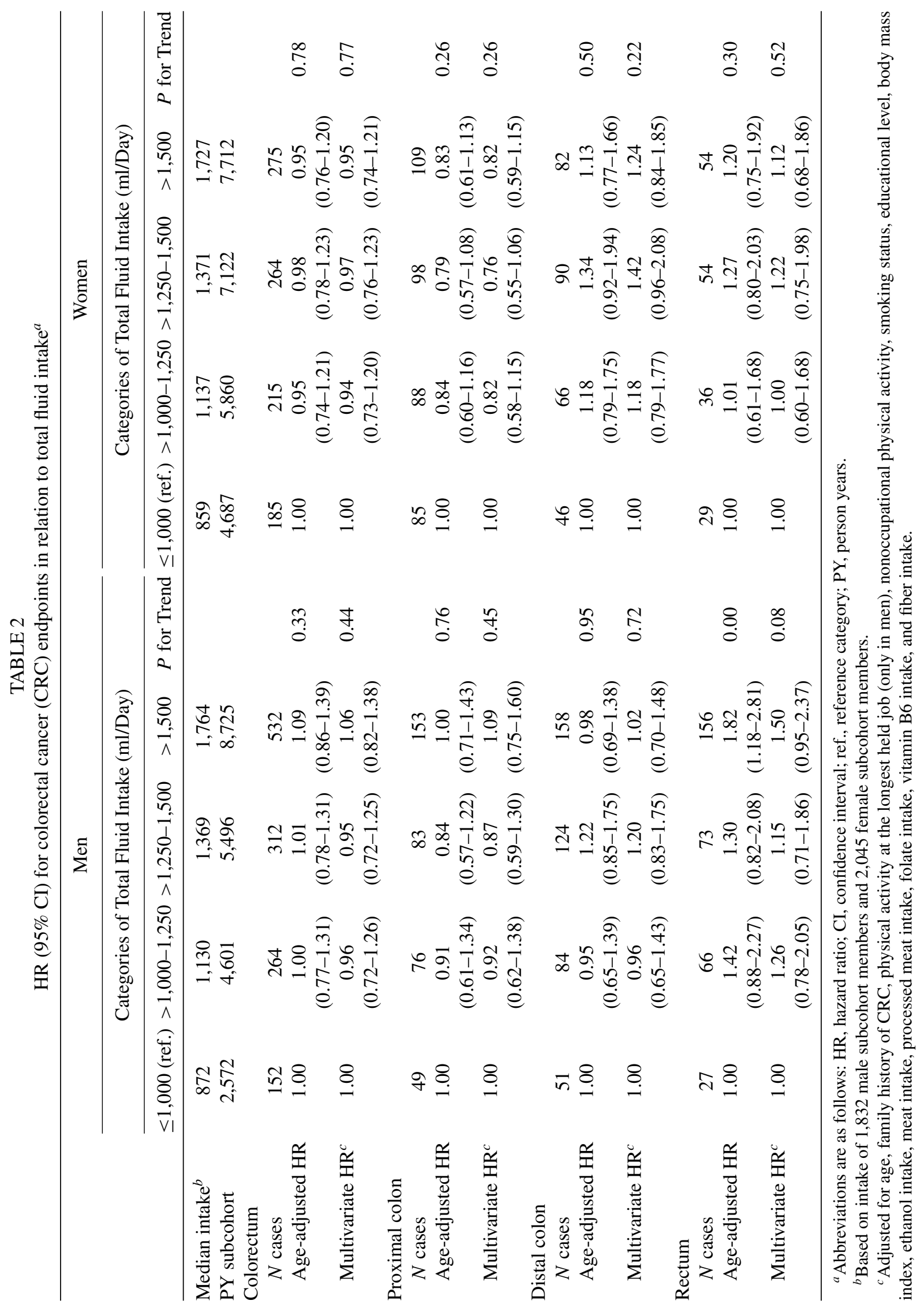




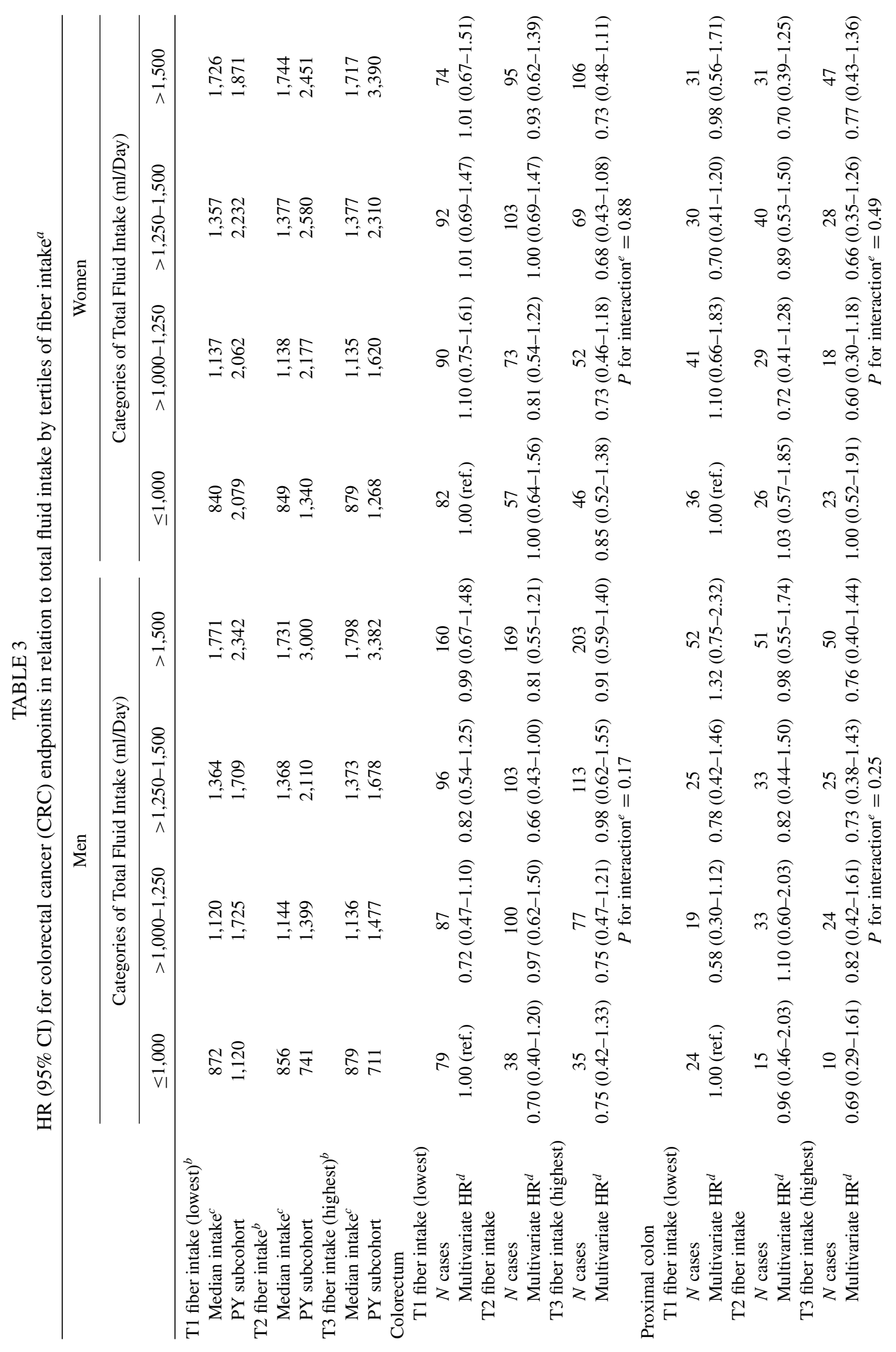




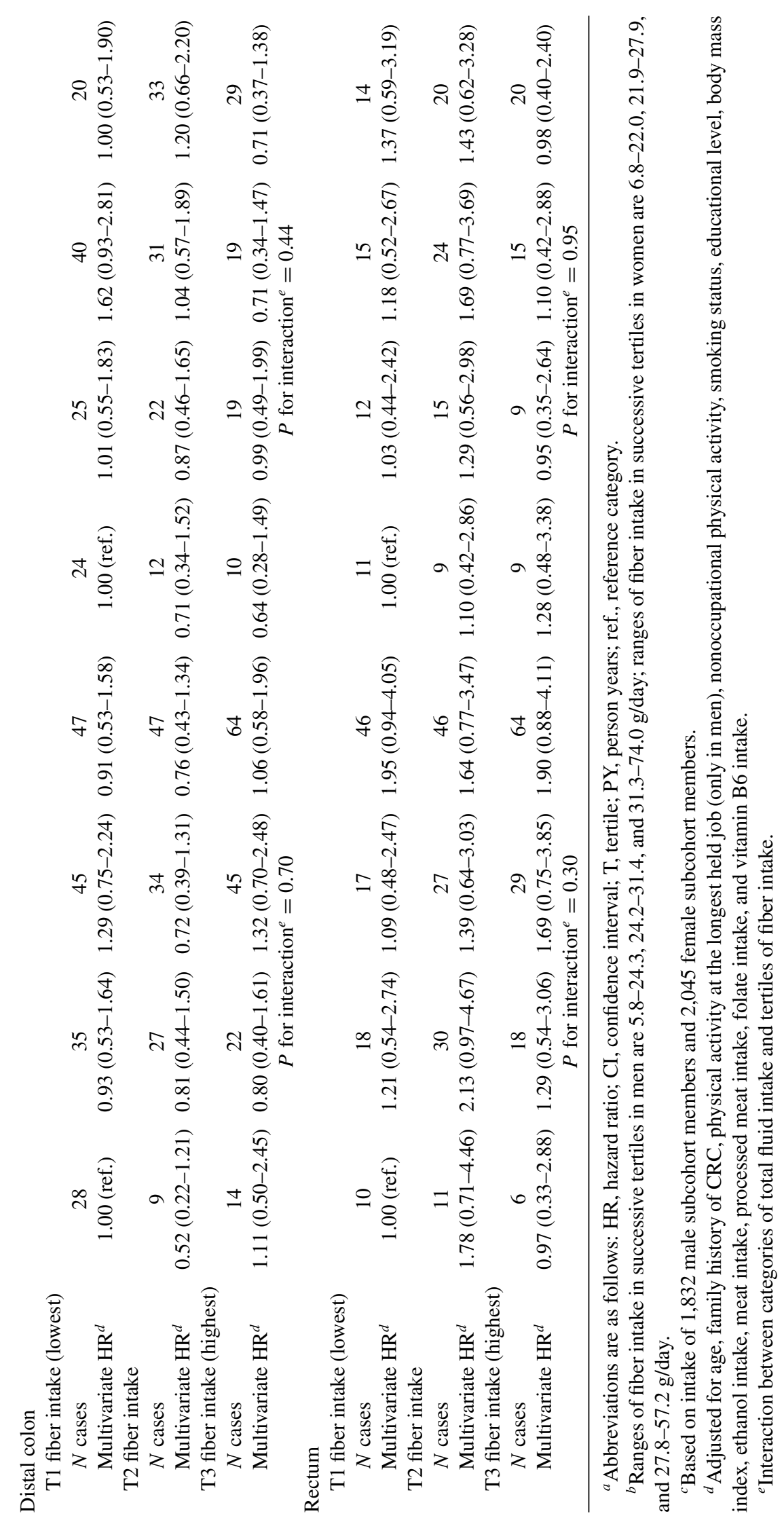


intake was analyzed continuously with an increment of 100 $\mathrm{ml} / \mathrm{day}$, a significantly increased HR for rectal cancer in men was present in the first tertile of fiber intake (HR $=1.05,95 \%$ $\mathrm{CI}=1.00-1.10$; data not shown).

Tables 4 and 5 show the age-adjusted and multivariate HRs (95\% CIs) for the association of intake of water, coffee, tea, milk, and alcoholic beverages with colorectal cancer endpoints in men and women, respectively. After adjustment for potential confounders and mutual adjustment for fluid intake from other fluids, no dose-response relationship of intake of water, coffee, tea, milk, and alcoholic beverages with overall colorectal cancer risk was observed in either men or women. Analyses for colorectal cancer subsites also showed no dose-response relationship with proximal or distal colon cancer risk, yet a positive trend was present in the association of coffee intake with rectal cancer risk in men $(P$ trend $=0.05)$. HRs for rectal cancer in men who consumed $\leq 2,>2-4,>4-6$, and $>6$ cups of coffee per day were 1.00 (reference), $1.32(95 \% \mathrm{CI}=0.87-1.99), 1.50$ $(95 \% \mathrm{CI}=0.97-2.31)$, and 1.60 (95\% CI $=0.96-2.66)$. For tea intake in both men and women and milk intake in men, almost all risk estimates were below unity, with some reaching significance. Analyses on a continuous scale with an increment of $100 \mathrm{ml} /$ day furthermore showed a significantly lower $\mathrm{HR}$ for the association of milk intake with overall colorectal cancer risk in men ( $\mathrm{HR}=0.96,95 \% \mathrm{CI}=0.91-1.00$; data not shown).

When we additionally adjusted for frequency of constipation to check whether this may be an intermediate factor, some changes in estimates occurred. Instead of a nonsignificant positive trend in the association of total fluid intake with rectal cancer risk in men, a significant positive trend was observed. In addition, the positive trend in the association of coffee intake with rectal cancer risk in men strengthened (data not shown). To check whether this (non)significant positive trend in the association of total fluid intake with rectal cancer risk in men reflected a potential effect of coffee, an extra analysis was done in which we additionally adjusted for coffee intake. Regardless of adjustment for constipation, this analysis no longer showed a (non)significant positive trend in the association of total fluid intake with rectal cancer risk in men (data not shown). We also examined the association of total dietary water intake with colorectal cancer endpoints. In our population, $67 \%$ of total dietary water intake was derived from beverages and 33\% from foods. Comparable to the results of analyses for total fluid intake, results of analyses for total dietary water intake showed a nonsignificant positive trend for rectal cancer risk in men $(P$ trend $=0.06$ ). HRs for rectal cancer in subsequent quintiles of total dietary water intake were 1.00 (reference), 0.96 (95\% CI $=0.63-1.48), 1.29(95 \% \mathrm{CI}=0.85-1.94), 1.18$ (95\% CI $=$ $0.77-1.83$ ), and 1.48 (95\% CI $=0.94-2.33$ ). Also, when we additionally adjusted for frequency of constipation, a significant positive trend for rectal cancer risk in men was observed, with risk being significantly increased in the highest quintile of intake as compared with the lowest (data not shown). Exclusion of the first $2 \mathrm{yr}$ of follow-up to check for the influence of preclinical disease gave similar results in all analyses (data not shown).

\section{DISCUSSION}

In this large prospective cohort study, no dose-response relationship of total fluid intake and intake of water, coffee, tea, milk, and alcoholic beverages with overall colorectal cancer risk was observed in either men or women. Analyses for colorectal cancer subsites also showed no dose-response relationship with proximal or distal colon cancer risk. For rectal cancer risk in men, there was a nonsignificant positive trend for total fluid intake and a significant positive trend for coffee intake. However, a nonsignificant positive trend for total fluid intake was no longer observed when additional adjustment for coffee intake was made, suggesting a potential effect of coffee on rectal cancer risk but not of fluids in general. Tests for interaction between total fluid intake and fiber intake were not significant.

Contrary to our findings, previous case-control studies have supported an inverse association of total fluid intake and/or water intake with colorectal cancer endpoints in either men or women $(1,3,4)$. One case-control study found no association when they investigated the association of water intake with rectal cancer risk but observed an increased risk in men with both a low water intake and a low fiber intake (5). Our study is the first prospective cohort study conducted on the association of total fluid intake and intake of specific beverages with colorectal cancer endpoints and possible effect modification by fiber intake. An advantage of this study is the large number of colorectal cancer cases available for analysis that provided sufficient power to do analyses for colorectal cancer subsites, separately for men and women. It should be noted, however, that the number of distal colon and rectal cancer cases within tertiles of fiber intake in some instances was less than 10.

The different findings as compared with those in previous case-control studies could be the result of potential confounding, information bias, and selection bias in these studies. The NLCS allowed us to adjust for multiple potential confounders because of the measurement of many risk factors at baseline, making confounding less likely. In addition, the prospective design and high completeness of follow-up of cancer incidence ( $>96 \%$ [22]) minimize the probability of information and selection bias to occur. The null association presently observed between water intake and colorectal cancer endpoints, nevertheless, could have resulted from the small contrast in water intake. There may have also been misclassification of intake, which, if independent of the outcome, would most likely lead to attenuation of the associations. Misclassification of intake cannot be ruled out because intake was based on a single measurement at baseline, which may not be representative of intake over $13.3 \mathrm{yr}$. However, the FFQ was shown to be representative over a period of at least $5 \mathrm{yr}(16)$.

When we investigated the association of coffee intake with colorectal cancer endpoints, we found a significant positive trend 
TABLE 4

HR $(95 \% \mathrm{CI})$ for colorectal cancer (CRC) endpoints in relation to intake of water, coffee, tea, milk, and the volume of alcoholic beverages in men $^{a}$

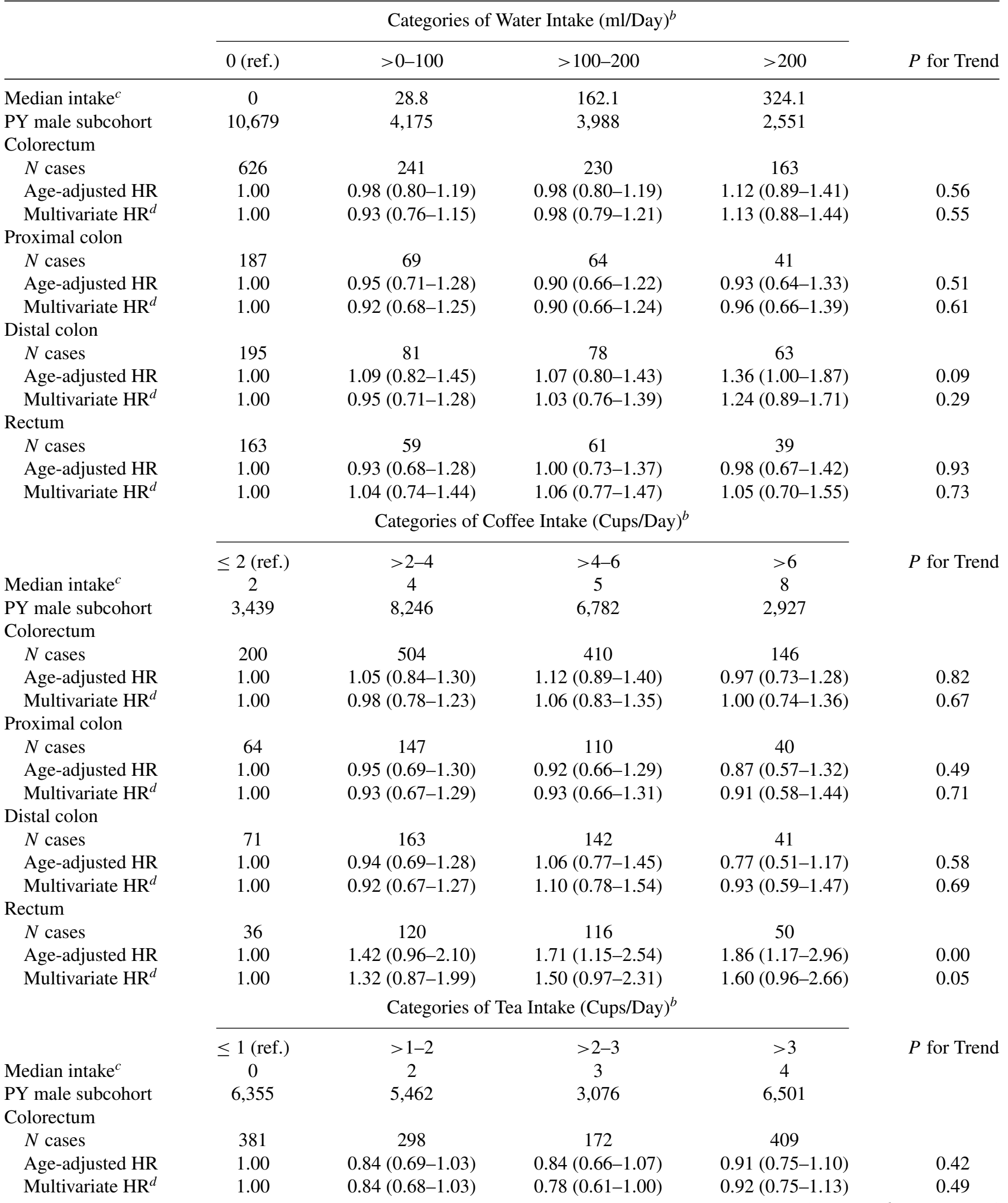


TABLE 4

HR (95\% CI) for colorectal cancer (CRC) endpoints in relation to intake of water, coffee, tea, milk, and the volume of alcoholic beverages in $\operatorname{men}^{a}$ (Continued)

\begin{tabular}{|c|c|c|c|c|c|}
\hline & \multicolumn{4}{|c|}{ Categories of Tea Intake (Cups/Day) $)^{b}$} & \multirow[b]{2}{*}{$P$ for Trend } \\
\hline & $\leq 1$ (ref.) & $>1-2$ & $>2-3$ & $>3$ & \\
\hline \multicolumn{6}{|l|}{ Proximal colon } \\
\hline$N$ cases & 100 & 82 & 60 & 119 & \\
\hline Age-adjusted HR & 1.00 & $0.91(0.66-1.24)$ & $1.18(0.83-1.67)$ & $1.01(0.76-1.35)$ & 0.67 \\
\hline Multivariate $\mathrm{HR}^{d}$ & 1.00 & $0.92(0.66-1.27)$ & $1.14(0.79-1.65)$ & $1.03(0.75-1.41)$ & 0.64 \\
\hline \multicolumn{6}{|l|}{ Distal colon } \\
\hline$N$ cases & 118 & 106 & 57 & 136 & \\
\hline Age-adjusted HR & 1.00 & $1.02(0.77-1.36)$ & $0.92(0.65-1.31)$ & $1.01(0.77-1.34)$ & 0.98 \\
\hline Multivariate $\mathrm{HR}^{d}$ & 1.00 & $1.00(0.75-1.35)$ & $0.81(0.57-1.16)$ & $0.99(0.73-1.33)$ & 0.78 \\
\hline \multicolumn{6}{|l|}{ Rectum } \\
\hline$N$ cases & 116 & 71 & 35 & 100 & \\
\hline Age-adjusted HR & 1.00 & $0.69(0.50-0.95)$ & $0.59(0.39-0.88)$ & $0.78(0.58-1.05)$ & 0.11 \\
\hline \multirow[t]{3}{*}{ Multivariate $\mathrm{HR}^{d}$} & 1.00 & $0.72(0.52-1.00)$ & $0.65(0.43-0.99)$ & $0.85(0.63-1.16)$ & 0.36 \\
\hline & \multicolumn{4}{|c|}{ Categories of Milk Intake (Glasses/Day) ${ }^{b}$} & \\
\hline & 0 (ref.) & $>0-1$ & $>1-2$ & $>2$ & $P$ for Trend \\
\hline Median intake ${ }^{c}$ & 0 & 0.7 & 1.4 & 2.8 & \\
\hline PY male subcohort & 3,264 & 9,835 & 5,511 & 2,784 & \\
\hline \multicolumn{6}{|l|}{ Colorectum } \\
\hline$N$ cases & 232 & 545 & 350 & 133 & \\
\hline Age-adjusted HR & 1.00 & $0.75(0.61-0.92)$ & $0.88(0.70-1.11)$ & $0.66(0.50-0.88)$ & 0.08 \\
\hline Multivariate $\mathrm{HR}^{d}$ & 1.00 & $0.74(0.59-0.92)$ & $0.86(0.68-1.09)$ & $0.68(0.50-0.92)$ & 0.13 \\
\hline \multicolumn{6}{|l|}{ Proximal colon } \\
\hline$N$ cases & 61 & 155 & 102 & 43 & \\
\hline Age-adjusted HR & 1.00 & $0.83(0.60-1.15)$ & $0.99(0.70-1.40)$ & $0.90(0.59-1.37)$ & 0.92 \\
\hline Multivariate $\mathrm{HR}^{d}$ & 1.00 & $0.82(0.59-1.14)$ & $0.95(0.67-1.35)$ & $0.84(0.53-1.32)$ & 0.82 \\
\hline \multicolumn{6}{|l|}{ Distal colon } \\
\hline$N$ cases & 78 & 180 & 122 & 37 & \\
\hline Age-adjusted HR & 1.00 & $0.77(0.58-1.03)$ & $0.94(0.69-1.29)$ & $0.59(0.39-0.90)$ & 0.15 \\
\hline Multivariate $\mathrm{HR}^{d}$ & 1.00 & $0.78(0.58-1.06)$ & $0.95(0.68-1.33)$ & $0.67(0.42-1.07)$ & 0.41 \\
\hline \multicolumn{6}{|l|}{ Rectum } \\
\hline$N$ cases & 56 & 149 & 82 & 35 & \\
\hline Age-adjusted HR & 1.00 & $0.91(0.66-1.27)$ & $0.87(0.61-1.25)$ & $0.80(0.51-1.26)$ & 0.31 \\
\hline \multirow[t]{3}{*}{ Multivariate $\mathrm{HR}^{d}$} & 1.00 & $0.93(0.66-1.31)$ & $0.87(0.59-1.28)$ & $0.79(0.49-1.27)$ & 0.28 \\
\hline & \multicolumn{4}{|c|}{ Categories of Intake of the Volume of Alcoholic Beverages (ml/Day) ${ }^{b}$} & \\
\hline & 0 (ref.) & $>0-100$ & $>100-200$ & $>200$ & $P$ for Trend \\
\hline Median intake ${ }^{c}$ & 0 & 40.7 & 145.4 & 314.6 & \\
\hline PY male subcohort & 2,973 & 8,704 & 4,027 & 5,689 & \\
\hline \multicolumn{6}{|l|}{ Colorectum } \\
\hline$N$ cases & 151 & 513 & 245 & 351 & \\
\hline Age-adjusted HR & 1.00 & $1.22(0.96-1.54)$ & $1.28(0.98-1.68)$ & $1.34(1.04-1.73)$ & 0.03 \\
\hline Multivariate $\mathrm{HR}^{d}$ & 1.00 & $1.19(0.92-1.52)$ & $1.20(0.88-1.63)$ & $1.32(0.94-1.85)$ & 0.16 \\
\hline \multicolumn{6}{|l|}{ Proximal colon } \\
\hline$N$ cases & 46 & 165 & 57 & 93 & \\
\hline Age-adjusted HR & 1.00 & $1.25(0.88-1.78)$ & $0.95(0.62-1.44)$ & $1.16(0.79-1.70)$ & 0.95 \\
\hline Multivariate $\mathrm{HR}^{d}$ & 1.00 & $1.31(0.91-1.89)$ & $1.11(0.69-1.79)$ & $1.58(0.94-2.66)$ & 0.16 \\
\hline
\end{tabular}

(Continued on next page) 
TABLE 4

HR (95\% CI) for colorectal cancer (CRC) endpoints in relation to intake of water, coffee, tea, milk, and the volume of alcoholic beverages in $\operatorname{men}^{a}$ (Continued)

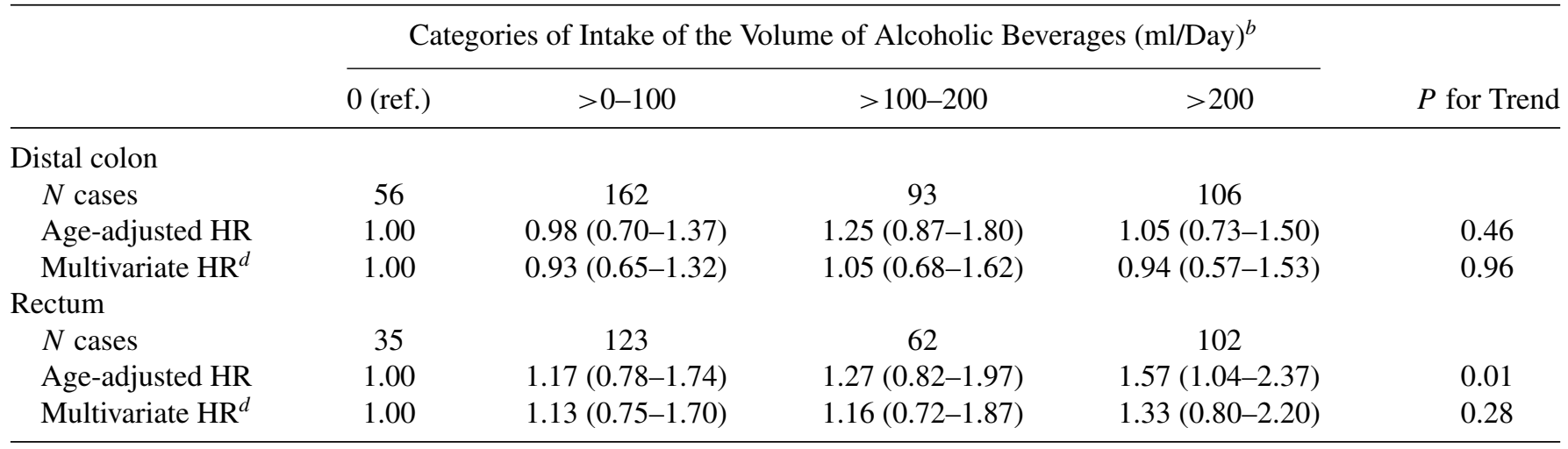

${ }^{a}$ Abbreviations are as follows: HR, hazard ratio; CI, confidence interval; PY, person years.

${ }^{b}$ The average size of a coffee/tea cup measured $125 \mathrm{ml}$, of a glass $175 \mathrm{ml}$, of a beer glass $200 \mathrm{ml}$, of a wine glass $105 \mathrm{ml}$, of a sherry glass 80 $\mathrm{ml}$, and of a liqueur/liquor glass $45 \mathrm{ml}$.

${ }^{c}$ Based on intake of 1,832 male subcohort members.

${ }^{d}$ Adjusted for age, family history of CRC, physical activity at the longest held job, nonoccupational physical activity, smoking status, educational level, body mass index, ethanol intake, meat intake, processed meat intake, folate intake, vitamin B6 intake, fiber intake, and fluid intake from other fluids.

for rectal cancer risk in men. Previous findings regarding the association of coffee intake with colorectal cancer endpoints have been inconsistent (7), although for colon cancer, most casecontrol studies have found an inverse association $(9,11)$. This is in line with findings of coffee containing compounds that have anticarcinogenic properties $(23,24)$ and with Brown et al. (25) who reported coffee to stimulate distal colonic motility (thus reducing the exposure time to carcinogens in the colon). Following this motility observation, an inverse association with (distal) colon cancer risk may have been expected in our study for coffee intake in particular. Instead, we observed no association with proximal or distal colon cancer risk and a positive trend for rectal cancer risk in men that strengthened when additional adjustment for frequency of constipation was made. A possible explanation for this positive trend could be the effect of some carcinogenic component present in coffee. An example may be acrylamide, but acrylamide was not found to be associated with risk of rectal cancer, colon cancer, or overall colorectal cancer in the NLCS (26). Alternatively, it cannot be ruled out that residual confounding partly affected our results. Coffee intake, for example, is associated with smoking, higher alcohol consumption, and physical inactivity $(9,27)$; and although we corrected for these factors, confounding may not have been completely removed. Residual confounding by smoking or alcohol consumption could perhaps also partly explain why coffee intake was associated with rectal cancer risk in men but not women, as smoking was more prevalent and mean ethanol intake was higher among male subcohort members than among female subcohort members.
With respect to intake of tea, milk, and alcoholic beverages, no dose-response relationship with colorectal cancer endpoints was observed. However, some suggestion of an inverse association of tea and milk intake with colorectal cancer endpoints was present. In previous studies, tea intake has not been consistently associated with colorectal cancer risk $(8-10)$, yet a protective effect of tea is hypothesized because catechins in tea were shown to have anticarcinogenic activities (12). Milk intake, especially calcium in milk, has previously been associated with a decreased colorectal cancer risk (7). The evidence for this includes a pooled analysis of 10 cohort studies, including the NLCS (28). Finally, intake of alcoholic beverages and ethanol have been associated with an increased colorectal cancer risk (7). In the NLCS, ethanol intake was shown to be associated with the risk of colorectal cancer-mostly rectal cancer-in men after $13.3 \mathrm{yr}$ follow-up (29). Therefore, the absence of an association of intake of alcoholic beverages with colorectal cancer endpoints in our study may be explained by the fact that we corrected for ethanol intake. To check how correction for ethanol intake influenced our results, an extra analysis was performed in which no adjustment for ethanol intake was made. Results of this analysis showed a significant positive association for rectal cancer risk in men for intake of alcoholic beverages as well as total fluid intake.

In conclusion, total fluid intake was not associated with colorectal cancer risk in either men or women. There was no evidence that fiber intake modified associations. Of the specific beverages, coffee intake was positively associated with rectal cancer risk in men. 
TABLE 5

HR (95\% CI) for colorectal cancer (CRC) endpoints in relation to intake of water, coffee, tea, milk, and the volume of alcoholic beverages in women ${ }^{a}$

\begin{tabular}{|c|c|c|c|c|c|}
\hline & \multicolumn{4}{|c|}{ Categories of Water Intake (ml/Day) $)^{b}$} & \multirow[b]{2}{*}{$P$ for Trenc } \\
\hline & 0 (ref.) & $>0-100$ & $>100-200$ & $>200$ & \\
\hline Median intake ${ }^{c}$ & 0 & 46.8 & 162.1 & 324.1 & \\
\hline PY female subcohort & 10,418 & 5,058 & 5,776 & 4,130 & \\
\hline \multicolumn{6}{|l|}{ Colorectum } \\
\hline$N$ cases & 401 & 185 & 192 & 161 & \\
\hline Age-adjusted HR & 1.00 & $0.96(0.78-1.19)$ & $0.88(0.71-1.08)$ & $1.03(0.82-1.29)$ & 0.77 \\
\hline Multivariate $\mathrm{HR}^{d}$ & 1.00 & $0.97(0.78-1.20)$ & $0.87(0.70-1.08)$ & $1.00(0.79-1.26)$ & 0.59 \\
\hline \multicolumn{6}{|l|}{ Proximal colon } \\
\hline$N$ cases & 163 & 77 & 68 & 72 & \\
\hline Age-adjusted HR & 1.00 & $0.98(0.73-1.31)$ & $0.77(0.57-1.04)$ & $1.12(0.83-1.52)$ & 0.91 \\
\hline Multivariate $\mathrm{HR}^{d}$ & 1.00 & $0.97(0.72-1.32)$ & $0.76(0.56-1.05)$ & $1.09(0.79-1.50)$ & 0.81 \\
\hline \multicolumn{6}{|l|}{ Distal colon } \\
\hline$N$ cases & 117 & 56 & 59 & 52 & \\
\hline Age-adjusted HR & 1.00 & $1.00(0.72-1.41)$ & $0.94(0.68-1.31)$ & $1.14(0.81-1.62)$ & 0.66 \\
\hline Multivariate $\mathrm{HR}^{d}$ & 1.00 & $1.03(0.73-1.45)$ & $0.95(0.67-1.33)$ & $1.17(0.81-1.67)$ & 0.61 \\
\hline \multicolumn{6}{|l|}{ Rectum } \\
\hline$N$ cases & 76 & 34 & 40 & 23 & \\
\hline Age-adjusted HR & 1.00 & $0.94(0.62-1.43)$ & $0.98(0.66-1.46)$ & $0.76(0.47-1.24)$ & 0.37 \\
\hline \multirow[t]{3}{*}{ Multivariate $\mathrm{HR}^{d}$} & 1.00 & $0.96(0.63-1.45)$ & $1.00(0.67-1.51)$ & $0.73(0.45-1.18)$ & 0.32 \\
\hline & \multicolumn{4}{|c|}{ Categories of Coffee Intake (Cups/Day) ${ }^{b}$} & \\
\hline & $\leq 2$ (ref.) & $>2-4$ & $>4-6$ & $>6$ & $P$ for Trend \\
\hline Median intake ${ }^{c}$ & 2 & 4 & 6 & 8 & \\
\hline PY female subcohort & 5,121 & 11,937 & 6,639 & 1,684 & \\
\hline \multicolumn{6}{|l|}{ Colorectum } \\
\hline$N$ cases & 206 & 425 & 245 & 63 & \\
\hline Age-adjusted HR & 1.00 & $0.93(0.76-1.14)$ & $0.99(0.79-1.24)$ & $1.08(0.76-1.53)$ & 0.71 \\
\hline Multivariate $\mathrm{HR}^{d}$ & 1.00 & $0.91(0.74-1.13)$ & $0.96(0.75-1.23)$ & $1.07(0.74-1.55)$ & 0.85 \\
\hline \multicolumn{6}{|l|}{ Proximal colon } \\
\hline$N$ cases & 84 & 175 & 95 & 26 & \\
\hline Age-adjusted HR & 1.00 & $0.96(0.72-1.27)$ & $0.96(0.70-1.32)$ & $1.14(0.70-1.84)$ & 0.84 \\
\hline Multivariate $\mathrm{HR}^{d}$ & 1.00 & $0.93(0.69-1.25)$ & $0.91(0.64-1.28)$ & $1.12(0.67-1.88)$ & 0.98 \\
\hline \multicolumn{6}{|l|}{ Distal colon } \\
\hline$N$ cases & 54 & 135 & 81 & 14 & \\
\hline Age-adjusted HR & 1.00 & $1.13(0.81-1.58)$ & $1.21(0.84-1.75)$ & $0.84(0.45-1.57)$ & 0.78 \\
\hline Multivariate $\mathrm{HR}^{d}$ & 1.00 & $1.19(0.85-1.68)$ & $1.30(0.88-1.93)$ & $0.96(0.51-1.80)$ & 0.48 \\
\hline \multicolumn{6}{|l|}{ Rectum } \\
\hline$N$ cases & 40 & 73 & 42 & 18 & \\
\hline Age-adjusted HR & 1.00 & $0.83(0.56-1.24)$ & $0.86(0.55-1.34)$ & $1.58(0.88-2.82)$ & 0.48 \\
\hline \multirow[t]{3}{*}{ Multivariate $\mathrm{HR}^{d}$} & 1.00 & $0.80(0.53-1.20)$ & $0.79(0.49-1.27)$ & $1.41(0.75-2.63)$ & 0.76 \\
\hline & \multicolumn{4}{|c|}{ Categories of Tea Intake (Cups/Day $)^{b}$} & \\
\hline & $\leq 1$ (ref.) & $>1-2$ & $>2-3$ & $>3$ & $P$ for Trend \\
\hline Median intake ${ }^{c}$ & 0 & 2 & 3 & 4 & \\
\hline PY female subcohort & 5,375 & 5,846 & 4,209 & 9,951 & \\
\hline \multicolumn{6}{|l|}{ Colorectum } \\
\hline$N$ cases & 220 & 193 & 141 & 385 & \\
\hline Age-adjusted HR & 1.00 & $0.81(0.64-1.03)$ & $0.77(0.60-1.00)$ & $0.89(0.72-1.09)$ & 0.44 \\
\hline Multivariate $\mathrm{HR}^{d}$ & 1.00 & $0.82(0.64-1.05)$ & $0.76(0.58-1.00)$ & $0.92(0.74-1.14)$ & 0.66 \\
\hline
\end{tabular}


TABLE 5

HR $(95 \% \mathrm{CI})$ for colorectal cancer (CRC) endpoints in relation to intake of water, coffee, tea, milk, and the volume of alcoholic beverages in women ${ }^{a}$ (Continued)

\begin{tabular}{|c|c|c|c|c|c|}
\hline & & Categories o & Intake (Cups/Day) & & \\
\hline & $\leq 1$ (ref.) & $>1-2$ & $>2-3$ & $>3$ & $P$ for Trend \\
\hline Proximal colon & & & & & \\
\hline$N$ cases & 93 & 76 & 53 & 158 & \\
\hline Age-adjusted HR & 1.00 & $0.78(0.56-1.09)$ & $0.70(0.48-1.01)$ & $0.86(0.65-1.14)$ & 0.44 \\
\hline Multivariate $\mathrm{HR}^{d}$ & 1.00 & $0.78(0.55-1.09)$ & $0.68(0.46-0.99)$ & $0.89(0.67-1.20)$ & 0.65 \\
\hline Distal colon & & & & & \\
\hline$N$ cases & 60 & 65 & 44 & 115 & \\
\hline Age-adjusted HR & 1.00 & $1.04(0.72-1.51)$ & $0.95(0.63-1.44)$ & $1.02(0.73-1.41)$ & 0.99 \\
\hline Multivariate $\mathrm{HR}^{d}$ & 1.00 & $1.07(0.73-1.56)$ & $0.96(0.63-1.46)$ & $1.05(0.74-1.49)$ & 0.87 \\
\hline Rectum & & & & & \\
\hline$N$ cases & 39 & 37 & 25 & 72 & \\
\hline Age-adjusted HR & 1.00 & $0.90(0.57-1.44)$ & $0.82(0.49-1.39)$ & $0.95(0.63-1.43)$ & 0.87 \\
\hline Multivariate $\mathrm{HR}^{d}$ & 1.00 & $0.94(0.58-1.51)$ & $0.83(0.49-1.40)$ & $1.00(0.66-1.51)$ & 0.98 \\
\hline & & Categories of & Intake (Glasses/Da & & \\
\hline & 0 (ref.) & $>0-1$ & $>1-2$ & $>2$ & $P$ for Trend \\
\hline Median intake ${ }^{c}$ & 0 & 0.7 & 1.4 & 2.6 & \\
\hline PY female subcohort & 3,993 & 11,083 & 7,268 & 3,038 & \\
\hline Colorectum & & & & & \\
\hline$N$ cases & 158 & 410 & 262 & 109 & \\
\hline Age-adjusted HR & 1.00 & $0.93(0.74-1.17)$ & $0.91(0.71-1.16)$ & $0.93(0.69-1.26)$ & 0.58 \\
\hline Multivariate $\mathrm{HR}^{d}$ & 1.00 & 0.95 (0.75-1.19) & $0.93(0.72-1.20)$ & $0.94(0.68-1.30)$ & 0.67 \\
\hline Proximal colon & & & & & \\
\hline$N$ cases & 67 & 163 & 100 & 50 & \\
\hline Age-adjusted HR & 1.00 & $0.89(0.66-1.22)$ & $0.84(0.60-1.17)$ & $1.04(0.70-1.56)$ & 0.91 \\
\hline Multivariate $\mathrm{HR}^{d}$ & 1.00 & $0.91(0.66-1.24)$ & $0.90(0.63-1.29)$ & $1.08(0.70-1.68)$ & 0.83 \\
\hline Distal colon & & & & & \\
\hline$N$ cases & 36 & 131 & 88 & 29 & \\
\hline Age-adjusted HR & 1.00 & 1.35 (0.92-1.99) & $1.38(0.92-2.07)$ & $1.08(0.65-1.80)$ & 0.67 \\
\hline Multivariate $\mathrm{HR}^{d}$ & 1.00 & $1.40(0.94-2.07)$ & $1.41(0.93-2.15)$ & $1.14(0.66-1.94)$ & 0.54 \\
\hline Rectum & & & & & \\
\hline$N$ cases & 37 & 69 & 46 & 21 & \\
\hline Age-adjusted HR & 1.00 & $0.66(0.44-1.00)$ & $0.67(0.43-1.05)$ & $0.74(0.42-1.30)$ & 0.31 \\
\hline Multivariate $\mathrm{HR}^{d}$ & 1.00 & $0.66(0.44-1.01)$ & $0.65(0.40-1.04)$ & $0.68(0.38-1.23)$ & 0.20 \\
\hline & Cate & s of Intake of the & e of Alcoholic Bev & es $(\mathrm{ml} / \mathrm{Day})^{b}$ & \\
\hline & 0 (ref.) & $>0-100$ & $>100-200$ & $>200$ & $P$ for Trend \\
\hline Median intake ${ }^{c}$ & 0 & 22.8 & 137.2 & 266.2 & \\
\hline PY female subcohort & 8,023 & 13,274 & 2,639 & 1,445 & \\
\hline Colorectum & & & & & \\
\hline$N$ cases & 315 & 478 & 88 & 58 & \\
\hline Age-adjusted HR & 1.00 & $0.93(0.78-1.11)$ & $0.87(0.65-1.15)$ & $1.13(0.80-1.60)$ & 0.86 \\
\hline Multivariate $\mathrm{HR}^{d}$ & 1.00 & $0.89(0.73-1.08)$ & $0.69(0.45-1.06)$ & $0.72(0.37-1.41)$ & 0.14 \\
\hline Proximal colon & & & & & \\
\hline$N$ cases & 129 & 196 & 29 & 26 & \\
\hline Age-adjusted HR & 1.00 & $0.94(0.74-1.20)$ & $0.70(0.45-1.08)$ & $1.28(0.80-2.03)$ & 0.84 \\
\hline Multivariate $\mathrm{HR}^{d}$ & 1.00 & $0.93(0.70-1.22)$ & $0.60(0.31-1.14)$ & $0.87(0.35-2.20)$ & 0.39 \\
\hline
\end{tabular}


TABLE 5

HR (95\% CI) for colorectal cancer (CRC) endpoints in relation to intake of water, coffee, tea, milk, and the volume of alcoholic beverages in women ${ }^{a}$ (Continued)

\begin{tabular}{|c|c|c|c|c|c|}
\hline & \multicolumn{4}{|c|}{ Categories of the Intake of the Volume of Alcoholic Beverages (m1/Day) ${ }^{b}$} & \multirow[b]{2}{*}{$P$ for Trend } \\
\hline & 0 (ref.) & $>0-100$ & $>100-200$ & $>200$ & \\
\hline \multicolumn{6}{|l|}{ Distal colon } \\
\hline$N$ cases & 95 & 151 & 25 & 13 & \\
\hline Age-adjusted HR & 1.00 & $0.97(0.74-1.27)$ & $0.82(0.52-1.31)$ & $0.79(0.43-1.45)$ & 0.32 \\
\hline Multivariate $\mathrm{HR}^{d}$ & 1.00 & $0.92(0.69-1.24)$ & $0.63(0.34-1.17)$ & $0.45(0.16-1.26)$ & 0.23 \\
\hline \multicolumn{6}{|l|}{ Rectum } \\
\hline$N$ cases & 60 & 81 & 22 & 10 & \\
\hline Age-adjusted HR & 1.00 & $0.82(0.58-1.16)$ & $1.19(0.71-1.98)$ & $1.00(0.50-2.02)$ & 0.86 \\
\hline Multivariate $\mathrm{HR}^{d}$ & 1.00 & $0.82(0.55-1.20)$ & $1.04(0.47-2.29)$ & $0.71(0.17-2.93)$ & 0.53 \\
\hline
\end{tabular}

\section{ACKNOWLEDGMENTS}

This project was conducted within the Joint Research Program of the Dutch water companies by researchers from Maastricht University and Kiwa Water Research. External review of the design and results was conducted by a Scientific Advisory Committee consisting of P. Hunter (University of East Anglia, Norwich, United Kingdom), R. Rylander (Sweden), and M. I. Sinclair (Water Quality Research Australia Limited, Monash University, Australia). The authors are much indebted for their valuable comments and would also like to thank Margreet Mons for initiating this project, involvement in the design and data collection, and advice. Furthermore, we are indebted to the participants of this study and wish to thank the Dutch Cancer Society for financial support, the cancer registries (IKA, IKL, IKMN, IKN, IKO, IKR, IKST, IKW, IKZ and VIKC), and the Netherlands nationwide registry of pathology (PALGA). We also thank A. Volovics and A. Kester for statistical advice; S. van de Crommert, H. Brants, J. Nelissen, C. de Zwart, M. Moll, W. van Dijk, and A. Pisters for assistance; and H. van Montfort, T. van Moergastel, L. van den Bosch, R. Schmeitz, and J. Berben for programming assistance. None of the authors had a financial or personal conflict of interest. Sources of funding were 1) KIWA Water Research and 2) Dutch Cancer Society.

\section{REFERENCES}

1. Shannon J, White E, Shattuck AL, and Potter JD: Relationship of food groups and water intake to colon cancer risk. Cancer Epidemiol Biomarkers Prev 5, 495-502, 1996.

2. Altieri A, La Vecchia C, and Negri E: Fluid intake and risk of bladder and other cancers. Eur J Clin Nutr 57(2 Suppl), S59-S68, 2003.
3. Slattery ML, Caan BJ, Anderson KE, and Potter JD: Intake of fluids and methylxanthine-containing beverages: association with colon cancer. Int J Cancer 81, 199-204, 1999.

4. Tang R, Wang JY, Lo SK, and Hsieh LL: Physical activity, water intake and risk of colorectal cancer in Taiwan: a hospital-based case-control study. Int J Cancer 82, 484-489, 1999.

5. Murtaugh MA, Ma KN, Caan BJ, and Slattery ML: Association of fluids from beverages with risk of rectal cancer. Nutr Cancer 49, 25-31, 2004.

6. Health Council of the Netherlands: Guideline for Dietary Fiber Intake, Publication No. 2006/03. The Hague: Health Council of the Netherlands, 2006.

7. World Cancer Research Fund/American Institute for Cancer Research: Food, Nutrition, Physical Activity, and the Prevention of Cancer: A Global Perspective. Washington, DC: American Institute for Cancer Research, 2007.

8. Arab L and Il'yasova D: The epidemiology of tea consumption and colorectal cancer incidence. J Nutr 133, 3310S-3318S, 2003.

9. Tavani A and La Vecchia C: Coffee, decaffeinated coffee, tea, and cancer of the colon and rectum: a review of epidemiological studies, 1990-2003. Cancer Causes Control 15, 743-757, 2004.

10. Sun C, Yuan J, Koh W, and Yu MC: Green tea, black tea and colorectal cancer risk: a meta-analysis of epidemiologic studies. Carcinogenesis 27, 1301-1309, 2006

11. La Vecchia $\mathrm{C}$ and Tavani A: Coffee and cancer risk: an update. Eur J Cancer Prev 16, 385-389, 2007.

12. Nijveldt RJ, van Nood E, van Hoorn DE, Boelens PG, van Norren K, et al.: Flavonoids: a review of probable mechanisms of action and potential applications. Am J Clin Nutr 74, 418-425, 2001.

13. van den Brandt PA, Goldbohm RA, van't Veer P, Volvovics A, Hermus RJJ, et al.: A large-scale prospective cohort study on diet and cancer in the Netherlands. J Clin Epidemiol 43, 285-295, 1990.

14. Nevo Table: Dutch Food Composition Table 1986-1987. The Hague, Netherlands: Voorlichtingsbureau voor de Voeding, 1986.

15. Goldbohm RA, van den Brandt PA, Brants HAM, van't Veer P, Al M, et al.: Validation of a dietary questionnaire used in a large-scale prospective cohort study on diet and cancer. Eur J Clin Nutr 48, 253-265, 1994. 
16. Goldbohm RA, van't Veer P, van den Brandt PA, van't Hof MA, Brants HAM, et al.: Reproducibility of a food frequency questionnaire and stability of dietary habits determined from five annually repeated measurements. Eur J Clin Nutr 49, 420-429, 1995.

17. Casparie M, Tiebosch ATMG, Burger G, Blauwgeers H, Van de Pol A, et al.: Pathology databanking and biobanking in the Netherlands, a central role for PALGA, the nationwide histopathology and cytopathology data network and archive. Cell Oncol 29, 19-24, 2007.

18. van den Brandt PA, Schouten LJ, Goldbohm RA, Dorant E, and Hunen PMH: Development of a record linkage protocol for use in the Dutch Cancer Registry for Epidemiological Research. Int J Epidemiol 19, 553-558, 1990.

19. Barlow WE: Robust variance estimation for the case-cohort design. Biometrics 50, 1064-1072, 1994.

20. Schoenfeld D: Partial residuals for the proportional hazards regression model. Biometrika 69, 239-241, 1982.

21. National Academy of Sciences, Institute of Medicine, Food and Nutrition Board: Dietary Reference Intakes for Water, Potassium, Sodium, Chloride, and Sulfate. Washington, DC: National Academies Press, 2004.

22. Goldbohm RA, van den Brandt PA, and Dorant E: Estimation of the coverage of municipalities by cancer registries and PALGA using hospital discharge data. Tijdschr Soc Gezondheidsz 72, 80-84, 1994.
23. Mori H, Kawabata K, Matsunaga K, Ushida J, Fujii K, et al.: Chemopreventive effects of coffee bean and rice constituents on colorectal carcinogenesis. Biofactors 12, 101-105, 2000.

24. Cavin C, Holzhaeuser D, Scharf G, Constable A, Huber WW, et al.: Cafestol and kahweol, two coffee specific diterpenes with anticarcinogenic activity. Food Chem Toxicol 40, 1155-1163, 2002.

25. Brown SR, Cann PA, and Read NW: Effect of coffee on distal colon function. Gut 31, 450-453, 1990.

26. Hogervorst JG, Schouten LJ, Konings EJ, Goldbohm RA, and van den Brandt PA: Dietary acrylamide intake is not associated with gastrointestinal cancer risk. J Nutr 138, 2229-2236, 2008.

27. La Vecchia C, Negri E, Franceschi S, Parazzini F, and Decarli A: Differences in dietary intake with smoking, alcohol, and education [abstract]. Nutr Cancer 17, 297-304, 1992. Available: http://www.ncbi.nlm.nih.gov/pubmed/. Accessed 2008 November 17.

28. Cho E, Smith-Warner SA, Spiegelman D, Beeson WL, van den Brandt PA, et al.: Dairy foods, calcium, and colorectal cancer: a pooled analysis of 10 cohort studies. J Natl Cancer Inst 96, 1015-1022, 2004.

29. Bongaerts BW, van den Brandt PA, Goldbohm RA, de Goeij AF, and Weijenberg MP: Alcohol consumption, type of alcoholic beverage and risk of colorectal cancer at specific subsites. Int J Cancer 123, 2411-2417, 2008. 